\title{
Long and Short-term Volatility Comovements in the East Asian Stock
}

\author{
Jin Yong Yang ${ }^{1}$, Sang-Heon Lee ${ }^{2}$, In-Sung Yeo ${ }^{3}$ \\ ${ }^{1}$ Department of Computer Engineering, Hansung University, Seoul, Korea \\ ${ }^{2}$ College of Economics and Finance, Hanyang University, Seoul, Korea \\ ${ }^{3}$ Seoul National University, Seoul, Korea \\ Correspondence: Jin Yong Yang, Dept. of Computer Engineering, Hansung University at 116 Samseongyoro-16gil, \\ Seongbuk-gu, Seoul, 02876, Korea.
}

Received: December 20, 2016

Accepted: February 20, $2017 \quad$ Available online: February 22, 2017

doi:10.11114/aef.v4i3.2087

URL: https://doi.org/10.11114/aef.v4i3.2087

\begin{abstract}
This study analyzed volatility comovement and contagion in the stock markets of four countries (China, Japan, Korea, and Taiwan) in East Asia, which are closely connected with each other geographically and economically in terms of short-term and long-term perspectives. The volatility of stock returns has complex properties of not only volatility clustering, but also long memory, regime change, and substantial outliers. This study reviewed the volatility comovement and contagion in a stock market from long-term and short-term perspectives with the Bivariate Markov Switching Multifractal (BMSM) volatility model that is known for explaining such characteristics well, in spite of using small number of parameters. The empirical analysis results are as follows: China has no significant correlation with the other three countries. Therefore, China stock market is regarded as isolated or segmented market. The influence of the financial crisis on East Asian countries varies depending on the country. Regardless of the starting point of the crisis, Korea and Taiwan are shown to be vulnerable to external impact, compared to China and Japan. From the perspective of the nature of crisis, financial crisis that occurred in 1997 in East Asia and South Europe in 2011 were identified as local shocks as they had an impact on only a few countries, while the global crisis in 2008 was identified as global shock because it caused significant short-term and/or mid and long-term volatility of all countries.
\end{abstract}

Keywords: volatility, spillovers, comovement, bivariate Markov-switching multifractal model, Hamilton filter

\section{Introducation}

As for the economy in East Asia, comovement grows not only in the real economy, but also in the financial market due to the progress of globalization. However, unlike the phenomena of economic growth, comovements of financial markets are related to contagion of risk (volatility). As seen in the East Asian crisis in 1997, risk occurred in one country expands to other countries quickly, which shows high contagion. In addition, great external shock such as the global financial crisis in 2008 and Southern European sovereign debt crisis in 2011 gave one more shock to the East Asian financial market and confirmed its vulnerability to foreign impact. Among East Asian countries, China, Japan, Korea, and Taiwan are geographically close to each other. Especially Jorion (1989) argues that a common culture (Confucianism) may induce interdependencies among the stock markets in Mainland China and at least some others in East Asia. Nevertheless, these countries are different in terms of economic growth stage, external credibility, financial market development, market deregulation, liberalization, and fiscal soundness etc. Therefore, although all four countries are common in having increasing volatility and high contagion effects, there are differences in the level of the effects among them.

There are lots of research regarding Asian financial market's spillover or interconnectedness. Most studies report that the comovements exist. However, they show the other results in some countries. Perhaps the reason is due to the sample period, the sample countries, the methodologies, etc. The major studies include the following. Hung and Cheung (1995) find a long-run relationship among five Asian emerging stock marekts (Hong Kong, Korea, Malaysia, Singapore, and Thailand) but Kwan, Sim and Cotsomimtis (1995) observe that four of them (except Thailand) are not cointegrated. Leong and Felmingham (2003) analyze the interdependence of five East Asian stock price indices where some of the pairs of markets are found to be cointegrated. Johnson and Soenen (2002) use Geweke measures of feedback and find a statistically high percentage of contemporaneous association between Asian equity markets and Japan. And there are 
several research regarding ASEAN countries (Indonesia, Malaysia, Philippines, Singapore, and Thailand). Palac-McMiken (1997) conclude that 4 ASEAN markets are linked together with the exception of Indonesia. Furthermore Roca, Selvanathan, and Shepherd (1998) find that these ASEAN markets are related in the short-term, but not significantly linked in the long-run. Sharma and Wongbangpo (2002) analyze the degree of long-term and short-term comovements in stock markets of five ASEAN countries and find that there is a long-run relationship among the stock markets of all countries but Philippines. Click and Plummer (2005) find that ASEAN-5 stock markets are integrated in the economic sense, but that integration is far from complete therefore initiatives to further integrate the stock markets are feasible.

In addition, there are a number of studies on the impact of 1997 Asian Crisis (or 2008 Global Crisis) on the comovements of the Asian stock market. Yang et al. (2003) and Tan and Tse (2002) find that Asian stock markets in general have become more integrated after the 1997-1998 Asian currency crisis. Khan and Park (2009) presents empirical evidence of herding contagion in the Asian stock market during the 1997 Asian financial crisis, above and beyond macroeconomic fundamental driven comovements. Park (2010) finds that there is a strong comovement between Asian markets. Among those, the countries with more developed financial systems (i.e., Japan, Singapore and Hong Kong in Asia) exhibited stronger linkages to the rest of the Asian markets. Huyghebaert and Wang (2010) examines the degree of stock market integration in East Asia and find that after the Asian currency crisis, shocks in Hong Kong and Singapore largely affect other East Asia stock markets, except for those in Mainland China. Yang (2013) examines the changing nature of volatility spillovers among U.S. and eight East Asian stock markets between the Asian currency crisis and the U.S. subprime credit crisis and find that Asian stock markets are the markets to which volatility is spilled over unidirectionally from several other countries during the subprime credit crisis period, whereas it is not true during the Asian currency crisis period.

Previous studies that dealt with volatility contagion of stock markets in East Asian countries mainly focused on correlations, especially analyzed time-varying correlation and contagion effect. Kuper and Lestano (2007) use dynamic conditional correlation to examine the dynamic linkages among financial markets in Thailand and Indonesia. Thao et al. (2013) employed the constant conditional correlation (CCC) and the dynamic conditional correlation (DCC). They found that almost all the East Asian markets revealed higher correlations to other markets in the region than the United States, even during the crisis period. On the other hand, Choi (2006) also using CCC and DCC, showed that there was no strong evidence of time-varying correlations for the sample period (1991-2005) and weak evidence of time-varying correlation between some countries in the post-crisis period. Toyoshima and Hamori (2013) use asymmetric DCC model to analyze the correlation between the Japanese and Singaporean stock markets and find that financial integration has advanced because of their economic partnership agreement (JSEPA). Yilmaz (2010) analyzed returns of Asian stock market and volatility spillover by using the Diebold and Yilmaz (2009) approach and demonstrated high spillover in the case of major crisis.

Analysis mainly using GARCH model or VAR model has unit duration because they do not consider heterogeneous duration such as short term or mid and long term, which is the shortcoming of the models. Unlike the previous studies, this study uses the Bivariate Markov-Switching Multifractal (BMSM) volatility Model that Calvet et al. (2006) propose. To understand the reason for using the BMSM model, it is necessary to know the background from the model. Briefly, Markov-Switching Multifractal (MSM) model has been proposed in an attempt to explain comprehensively the stylized facts of financial time series. Already, it is investigated that volatility in financial time series exhibits several stylized facts. Some of these stylized facts are volatility clustering, long memory, fat-tailed distribution, regime switching, and substantial outliers. The models that expanded Engle's ARCH model (1982), which is a standard volatility model, and Bollerslev's GARCH model (1986), are presented in order to understand the characteristics of volatility better and increase forecast performance by explaining stylized facts. However, despite such effort, it is quite difficult to explain all stylized facts described above because it would bring ineffective results in terms of simplification of a model .

Unlike traditional approaches, Calvet and Fisher (2004) developed new volatility model, which is the Markov-Switching Multifractal (MSM) model having heterogeneous durations. Heterogeneous durations mean that there are short-, mid-, and long-term volatility components because MSM allows shocks (innovation term) to have different frequencies. For example, population aging or demographic change shock will have long-term frequency but market disturbances like noises will have (very) short-term frequency and business cycle shock will have mid-term frequency. MSM model can explain most of the characteristics described above well, in spite of its parsimonious form. In particular, it is reported that in-sample fit and out-of-sample forecasting showed outstanding results in compared to existing models including Regime-Switching GARCH model or Fractionally Integrated GARCH model (Calvet and Fisher (2004), Lux (2007), Lee and Kim (2015)). In addition, Calvet, Fisher and Thompson (2006) suggested the Bivariate MSM (BMSM) model by expanding univariate MSM model in order to consider the correlation between two factors. Therefore, since the study of Calvet et al. (2006) used the bivariate model that explains stylized facts of volatility and heterogeneous durations, it is appropriate to analyze long-term contagion of volatility. 
This study analyzed comovement and contagion of four countries in East Asia, including China, Japan, Korea, and Taiwan, with the BMSM model and reviewed the things that previous models did not catch. In particular, Idier (2011) introduced additional risk indicators such as the probability of a crisis and extreme comovement indicators to the BMSM model and specified volatility comovement analysis more. We follow Idier's approach (2011). From empirical applications to the four countries in East Asia, we find that China did not have high correlation with the other three countries. The influence of the financial crisis on East Asian countries varies depending on the country. Regardless of the starting point of the crisis, Korea and Taiwan are shown to be vulnerable to external impact, compared to China and Japan. From the perspective of the nature of crisis, financial crisis that occurred in 1997 in East Asia and South Europe in 2011 were identified as local shocks as they had impact on only a few countries, while the global crisis in 2008 was identified as global shock because it caused significant short-term and/or mid and long-term volatility of all countries.

The structure of this paper is as follows: Chapter 2 explains the analysis model, estimation methods, and calculation method of major correlation indicators. Chapter 3 describes the characteristics of data based on data and basic statistics. Chapter 4 interprets empirical analysis results and meaning of major correlation indicators. Chapter 5 summarizes research results and presents the conclusion and suggestions.

\section{Method}

\subsection{Bivariate Markov-switching Multifractal Volatility Model}

It Calvet and Fisher (2004) suggested the Markov-switching multifractal (MSM) model which analyzed the volatility with the components of heterogeneous durations and assigned multifractal structure to volatility. However, as the MSM model is a univariate model, it cannot analyze the correlation between two series. In order to complement such shortcomings, Calvet et al. (2006) suggested a bivariate MSM model that is an expanded model to consider the correlation between two markets.

Let's define the vector of returns as $r_{t}=\left(\begin{array}{l}r_{t}^{\alpha} \\ r_{t}^{\beta}\end{array}\right)$ for market $\alpha$ and $\beta$. The vector of the components at the k-th frequency is $C_{k t}=\left(\begin{array}{c}C_{k t}^{\alpha} \\ C_{k t}^{\beta}\end{array}\right) 1$. The period $t$ volatility is characterized by the $(2, \bar{k})$ matrix $C_{t}=\left(C_{1 t} ; C_{2 t} ; \ldots C_{\overline{k t}}\right)$, where $\overline{\mathrm{k}}$ is the index for the lowest frequency. Each row stands for each country's market indexed by $\mathrm{m}=\{\alpha, \beta\}^{2}$, while each column for a frequency $\mathrm{k}=\{1,2, \ldots, \overline{\mathrm{k}}\}$.

$$
C_{t}=\left(C_{1 t} ; C_{2 t} ; \ldots C_{\overline{k t}}\right)=\left(\left(\begin{array}{c}
C_{1 t}^{\alpha} \\
C_{1 t}^{\beta}
\end{array}\right) ; \quad\left(\begin{array}{c}
C_{2 t}^{\alpha} \\
C_{2 t}^{\beta}
\end{array}\right) ; \quad \ldots \quad ;\left(\begin{array}{c}
C_{\overline{k t}}^{\alpha} \\
C_{\overline{k t}}^{\beta}
\end{array}\right)\right)
$$

The vector of returns can be written as:

$$
r_{t}=\left(\begin{array}{c}
C_{t}^{\alpha 1 / 2} \\
C_{t}^{\beta^{1 / 2}}
\end{array}\right) * \varepsilon_{t}
$$

With $*$ the Hadamard product, $\mathrm{C}_{\mathrm{t}}^{\mathrm{m}}=\prod_{\mathrm{k}=1}^{\overline{\mathrm{k}}} \mathrm{C}_{\mathrm{kt}}^{\mathrm{m}}$ and $\varepsilon \in \mathbb{R}^{2}$ the vector of residuals which are IID Gaussian $(0, \Sigma)$ with

$$
\Sigma=\left(\begin{array}{cc}
\sigma_{\alpha}^{2} & \rho_{\varepsilon} \sigma_{\alpha} \sigma_{\beta} \\
\rho_{\varepsilon} \sigma_{\alpha} \sigma_{\beta} & \sigma_{\beta}^{2}
\end{array}\right)
$$

In period $t, \alpha$ or $\beta$ may be hit by an information arrival at frequency $\gamma_{k}$. The correlation between information arrivals is represented by a $\lambda \in[0 ; 1]$ coefficient. ${ }^{4}$ Let's consider the dummy variables $D_{k}^{\alpha}$ and $D_{k}^{\beta}$ which take values 1 if an information arrival occurs on component $k$ of series $\alpha$ or $\beta$ and 0 otherwise . The vector $D_{k}=\left(\begin{array}{c}D_{k}^{\alpha} \\ D_{k}^{\beta}\end{array}\right)$

\footnotetext{
${ }^{1}$ We mean volatility components by $C$, which is the first letter of "Component".

${ }^{2} \mathrm{We}$ mean market by $m$, which is the first letter of "market".

${ }^{3} \rho_{\varepsilon} \in[0 ; 1]$ denote the unconditional correlation between the residuals. According to Idier (2011), it is the first source of correlation between the two markets.
}

${ }^{4}$ Also, from Idier (2011), a second source of correlation is the correlation between information arrivals.

${ }^{5}$ We mean dummy variable by $D$, which is the first letter of "Dummy". 
is specified as IID. ${ }^{6}$ The arrival vector needs to be symmetric. $\left(\begin{array}{c}D_{k}^{\alpha} \\ D_{k}^{\beta}\end{array}\right) \equiv\left(\begin{array}{c}D_{k}^{\beta} \\ D_{k}^{\alpha}\end{array}\right)$

After that, we set as follows.

$$
\operatorname{Pr}\left(D_{\mathrm{k}}^{\alpha}=1\right)=1-\left(1-\gamma_{1}\right)^{\mathrm{b}^{\mathrm{k}-1}}
$$

We can set the conditional probability of information arrivals as follows.

$$
\operatorname{Pr}\left(D_{k}^{\beta}=1 \mid D_{k}^{\alpha}=1\right)=(1-\lambda) \gamma_{k}+\lambda^{7}
$$

The component $\mathrm{C}_{\mathrm{kt}}^{\mathrm{m}}$ is drawn from a binomial distribution taking value $\mathrm{c}^{\mathrm{m}}$ and $2-\mathrm{c}^{\mathrm{m}}$ with the same probability distribution:

$$
\mathrm{C}_{\mathrm{kt}}^{\mathrm{m}}=\mathrm{C}_{\mathrm{kt}-1}^{\mathrm{m}}+\mathrm{D}_{\mathrm{kt}}^{\mathrm{m}} *\left(\mathrm{C}-\mathrm{C}_{\mathrm{kt}-1}^{\mathrm{m}}\right)
$$

Finally, the correlation between $C^{\alpha}$ and $C^{\beta}$ under the bivariate binomial distribution $C$ is a last parameter of the dependency structure. ${ }^{8}$

The matrix $\left(p_{i j}\right)_{k}=\operatorname{Pr}\left(C_{k}=\left(c_{i}^{\alpha}, c_{j}^{\beta}\right)\right)$ with $i, j=\{H, L\}$ for high and low value is defined as

$$
\left[\begin{array}{ll}
\mathrm{p}_{\mathrm{LL}} & \mathrm{p}_{\mathrm{LH}} \\
\mathrm{p}_{\mathrm{HL}} & \mathrm{p}_{\mathrm{HH}}
\end{array}\right]_{\mathrm{k}}=\left[\begin{array}{cc}
\frac{1+\rho_{\mathrm{c}}^{*}}{4} & \frac{1-\rho_{\mathrm{c}}^{*}}{4} \\
\frac{1-\rho_{\mathrm{c}}^{*}}{4} & \frac{1+\rho_{\mathrm{c}}^{*}}{4}
\end{array}\right]_{\mathrm{k}}
$$

It is set that the binomial distribution is the same for all component $\mathrm{C}_{\mathrm{kt}}^{\mathrm{m}}$, no matter what $\mathrm{k}$ is, so that the $\mathrm{k}$ index may be omitted.

The probability that an information arrival coincides on both markets is given by

$$
\mathrm{d}_{11 \mathrm{k}}=\operatorname{Pr}\left(\mathrm{D}_{\mathrm{kt}}^{\beta}=1=\mathrm{D}_{\mathrm{kt}}^{\alpha}\right)=\operatorname{Pr}\left(\mathrm{D}_{\mathrm{kt}}^{\beta}=1 \mid \mathrm{D}_{\mathrm{kt}}^{\alpha}=1\right) \cdot \operatorname{Pr}\left(\mathrm{D}_{\mathrm{kt}}^{\alpha}=1\right)
$$

and similar for the probability that an information arrival only occurs on one of the two markets, or no information arrival on both markets. These different probabilities give the following $d_{k}$ matrices, with element $d_{i j k}$ where $i=D_{k t}^{\alpha}$ and $\mathrm{j}=\mathrm{D}_{\mathrm{kt}}^{\beta}$ :

$$
d_{k}=\left[\begin{array}{ll}
d_{11 k} & d_{10 k} \\
d_{01 k} & d_{00 k}
\end{array}\right]=\left[\begin{array}{cc}
{\left[(1-\lambda) \gamma_{k}+\lambda\right] \gamma_{k}} & \left(1-\gamma_{k}\right)(1-\lambda) \gamma_{k} \\
\left(1-\gamma_{k}\right)(1-\lambda) \gamma_{k} & {\left[1-\gamma_{k}(1-\lambda)\right]\left(1-\gamma_{k}\right)}
\end{array}\right]
$$

It is obtained for each $k$ that the random vector $C_{k t}$ can take four possible states: $s_{1}^{k}=\left(c_{0}^{\alpha}, c_{0}^{\beta}\right), s_{2}^{k}=\left(c_{0}^{\alpha}, c_{1}^{\beta}\right)$, $s_{3}^{k}=\left(c_{1}^{\alpha}, c_{0}^{\beta}\right), s_{4}^{k}=\left(c_{1}^{\alpha}, c_{1}^{\beta}\right)$ with $c_{1}^{m}=2-c_{0}^{m}$. The $d_{k}$ matrices potentiate the calculation of the transition matrix $\mathrm{T}_{\mathrm{k}}$ of the multipliers vector $\mathrm{C}_{\mathrm{kt}}=\left(\begin{array}{c}\mathrm{C}_{\mathrm{kt}}^{\alpha} \\ \mathrm{C}_{\mathrm{kt}}^{\beta}\end{array}\right)$ where each element is defined as

All calculations give ${ }^{10}$ :

$$
\mathrm{t}_{\mathrm{ij}}=\operatorname{Pr}\left(\mathrm{s}_{\mathrm{t}+1}^{\mathrm{k}}=\mathrm{s}_{\mathrm{j}}^{\mathrm{k}} \mid \mathrm{s}_{\mathrm{t}}^{\mathrm{k}}=\mathrm{s}_{\mathrm{i}}^{\mathrm{k}}\right), \quad i, j=\{1,2,3,4\}
$$

\footnotetext{
${ }^{6}$ It satisfies few conditions. See Calvet et al. (2006).
}

${ }^{7}$ The $\lambda$ is the unconditional correlation between information arrivals.

${ }^{8}$ See Idier (2011) p.13

${ }^{9} \rho_{c}^{*} \in[0 ; 1]$ is the correlation between components of frequency $k$ of series $\alpha$ and $\beta$.

${ }^{10}$ See Idier (2011) Appendix A. Transitions matrix. 


$$
\mathrm{T}_{\mathrm{k}}=\left(\begin{array}{cccc}
\Psi_{\mathrm{k}} & \Phi_{\mathrm{k}}-\left(\mathrm{d}_{00 \mathrm{k}}+\frac{\mathrm{d}_{01 \mathrm{k}}}{2}\right) & \Phi_{\mathrm{k}}-\left(\mathrm{d}_{00 \mathrm{k}}+\frac{\mathrm{d}_{01 \mathrm{k}}}{2}\right) & \Psi_{\mathrm{k}}-\left(\mathrm{d}_{00 \mathrm{k}}+\mathrm{d}_{01 \mathrm{k}}\right) \\
\Psi_{\mathrm{k}}-\left(\mathrm{d}_{00 \mathrm{k}}+\frac{\mathrm{d}_{01 \mathrm{k}}}{2}\right) & \Phi_{\mathrm{k}} & \Phi_{\mathrm{k}}-\left(\mathrm{d}_{00 \mathrm{k}}+\mathrm{d}_{01 \mathrm{k}}\right) & \Psi_{\mathrm{k}}-\left(\mathrm{d}_{00 \mathrm{k}}+\frac{\mathrm{d}_{01 \mathrm{k}}}{2}\right) \\
\Psi_{\mathrm{k}}-\left(\mathrm{d}_{00 \mathrm{k}}+\frac{\mathrm{d}_{01 \mathrm{k}}}{2}\right) & \Phi_{\mathrm{k}}-\left(\mathrm{d}_{00 \mathrm{k}}+\mathrm{d}_{01 \mathrm{k}}\right) & \Phi_{\mathrm{k}} & \Psi_{\mathrm{k}}-\left(\mathrm{d}_{00 \mathrm{k}}+\frac{\mathrm{d}_{01 \mathrm{k}}}{2}\right) \\
\Psi_{\mathrm{k}}-\left(\mathrm{d}_{00 \mathrm{k}}+\mathrm{d}_{01 \mathrm{k}}\right) & \Phi_{\mathrm{k}}-\left(\mathrm{d}_{00 \mathrm{k}}+\frac{\mathrm{d}_{01 \mathrm{k}}}{2}\right) & \Phi_{\mathrm{k}}-\left(\mathrm{d}_{00 \mathrm{k}}+\frac{\mathrm{d}_{01 \mathrm{k}}}{2}\right) & \Psi_{\mathrm{k}}
\end{array}\right)
$$

Finally, the volatility state transition matrix of asset returns A with elements $\left(a_{i j}\right)$ with $1 \leq \mathrm{i}, \mathrm{j} \leq 4^{\overline{\mathrm{k}}}$ is given by ${ }^{11}$ :

$$
a_{i j}=\operatorname{Pr}\left(S_{t+1}=S^{j} \mid S_{t}=S^{i}\right)^{12}
$$

The number of states grows geometrically with the number of frequencies. Calvet et al. (2006) develop a two-step ML optimization procedure to estimate the set of parameters $\varphi^{\prime}=\left(\sigma_{\alpha}, \sigma_{\beta}, c_{0}^{\alpha}, c_{0}^{\beta}, b, \gamma_{1}, \rho_{\varepsilon}, \lambda, \rho^{*}\right) \in \mathbb{R}^{9}$. It first estimates a combined bivariate which is the two univariate cases imposing the constraint that the frequencies are the same (which means the same $b$ and the same $\left.\gamma_{1}\right)$. The dependence structure is then calculated, i.e. the three other parameters $\left(\rho_{\varepsilon}, \rho^{*}\right.$ and $\lambda$ ) during the second step.

\subsection{Crisis Indicators}

Idier (2011) derives several useful crisis indicators from the results of the estimated BMSM model. These indicators are about extreme comovement, conditional probability of crisis, and long-term high or low volatility cycles. Whereas DCC model or previous correlation analysis mainly focuses on short-term volatility, these indicators have advantages in that they expanded the time series to short, mid, and long-term ones.

\subsubsection{Covariance}

$$
\operatorname{Cov}_{\mathrm{t}}\left(\mathrm{r}_{\mathrm{t}}^{\alpha}, \mathrm{r}_{\mathrm{t}}^{\beta}\right)=\rho_{\varepsilon} \sigma_{\alpha} \sigma_{\beta} \prod_{\mathrm{k}=1}^{\overline{\mathrm{k}}} \mathrm{E}\left[\left(\mathrm{C}_{\mathrm{kt}}^{\alpha} \mathrm{C}_{\mathrm{kt}}^{\beta}\right)^{\frac{1}{2}}\right]
$$

\subsubsection{Probability of a crisis}

The probability of crisis is a first indicator of interest. To identify crisis transmission between markets, joint probability to be in the highest volatility state in two markets is of interest. It is defined as follows:

$$
\operatorname{Pr}(\text { crisis })_{\mathrm{t}}=\operatorname{Pr}\left(\mathrm{C}_{1 \mathrm{t}}^{\alpha}=\cdots \mathrm{C}_{\overline{\mathrm{kt}}}^{\alpha}=\mathrm{c}_{0}^{\alpha} \text { and } \mathrm{C}_{1 \mathrm{t}}^{\beta}=\cdots \mathrm{C}_{\overline{\mathrm{kt}}}^{\beta}=\mathrm{c}_{0}^{\beta}\right)=\Pi_{\mathrm{t}} \cdot \delta_{1}
$$

with $\delta_{1}$ a vector of dimension $4^{\overline{\mathrm{k}}}$ with dirac elements $\delta_{1 \mathrm{i}}=1_{\left\{\mathrm{C}_{1 \mathrm{t}}^{\alpha}=\cdots \mathrm{C}_{\mathrm{kt}}^{\alpha}=c_{0}^{\alpha}\right\}} \times 1_{\left\{\mathrm{c}_{1 \mathrm{t}}^{\beta}=\cdots \mathrm{c}_{\mathrm{kt}}^{\beta}=c_{0}^{\beta}\right\}}$ for $\mathrm{i}=1$ to $4^{\overline{\mathrm{k}}}$, given that each component for a given series follows the same binomial distribution taking high value $c_{0}^{m}$ for $m=\{\alpha, \beta\}$ or low value $2-c_{0}^{m}$. A crisis is identified when the probability to be in the highest state of volatility reaches a defined threshold.

\subsubsection{Conditional Probability of a Crisis}

It is defined as the conditional probability to be in a high state of volatility in market $\alpha$, given that market $\beta$ is in a high volatility state. This represents the probability of crisis transmission between two markets and by using the Bayes theorem is as:

\footnotetext{
${ }^{11}$ The $\bar{k}$ is the number of frequencies in the model.

${ }^{12}$ " $S=\left(s^{1}, s^{2}, \ldots, s^{\bar{k}}\right)$ " is the vector of frequency states.
} 


$$
\begin{aligned}
& \operatorname{Pr}(\text { contagion })_{\mathrm{t}}=\operatorname{Pr}\left(\mathrm{C}_{1 \mathrm{t}}^{\alpha}=\cdots \mathrm{C}_{\mathrm{kt}}^{\alpha}=\mathrm{c}_{0}^{\alpha} \mid \mathrm{C}_{1 \mathrm{t}}^{\beta}=\cdots \mathrm{C}_{\overline{\mathrm{kt}}}^{\beta}=\mathrm{c}_{0}^{\beta}\right) \\
& =\frac{\operatorname{Pr}\left(\mathrm{C}_{1 \mathrm{t}}^{\alpha}=\cdots \mathrm{C}_{\mathrm{kt}}^{\alpha}=\mathrm{c}_{0}^{\alpha} \text { and } \mathrm{C}_{1 \mathrm{t}}^{\beta}=\cdots \mathrm{C}_{\overline{\mathrm{kt}}}^{\beta}=\mathrm{c}_{0}^{\beta}\right)}{\operatorname{Pr}\left(\mathrm{C}_{1 \mathrm{t}}^{\beta}=\cdots \mathrm{C}_{\mathrm{kt}}^{\beta}=\mathrm{c}_{0}^{\beta}\right)}=\frac{\Pi_{\mathrm{t}} \cdot \delta_{1}}{\Pi_{\mathrm{t}} \cdot \delta_{2}}
\end{aligned}
$$

with $\delta_{2}$ a vector of dimension $4^{\overline{\mathrm{k}}}$ with dirac elements $\delta_{2 \mathrm{i}}=1_{\left\{\mathrm{C}_{1 \mathrm{t}}^{\beta}=\cdots \mathrm{C}_{\mathrm{kt}}=c_{0}^{\beta}\right\}}$ for $\mathrm{i}=1$ to $4^{\overline{\mathrm{k}}}$.

This gives insights about how a market is influenced by the other and if high volatility states are transmitted to it.

\subsubsection{Long-term High and Low Volatility Cycle}

As previously, it is interesting to identify the long run cycles in volatility (high or low) that are shared between returns. For example, let us identify the low, long run cycle in volatility. From the different states $\mathrm{m}^{\mathrm{i}}$ in volatility with $\mathrm{i}=1$ to $4^{\overline{\mathrm{k}}}$ we simply keep the states for which the components with the lowest frequency (for $\mathrm{k}=\overline{\mathrm{k}}$ ) for the two returns series both have a low value $2-c_{0}^{\mathrm{m}}$. It means that the series may be hit on shorter run cycles by shocks, but the longest cycle (represented by the lowest frequency of jump in the component $\overline{\mathrm{k}}$ ) stays relatively stable. This probability to be in a low, long run cycle is thus written as:

$$
\operatorname{Pr}(\text { LLRC })_{\mathrm{t}}=\operatorname{Pr}\left(\mathrm{C}_{\overline{\mathrm{kt}}}^{\alpha}=\mathrm{C}_{\overline{\mathrm{k}} \mathrm{t}}^{\beta}=2-\mathrm{c}_{0}^{\alpha}\right)=\Pi_{\mathrm{t}} \cdot \delta_{3}
$$

with $\delta_{3}$ a vector of dimension $4^{\overline{\mathrm{k}}}$ with dirac elements $\delta_{3 \mathrm{i}}=1_{\left\{\mathrm{c}_{\mathrm{kt}}^{\alpha}=2-c_{0}^{\alpha}\right\}} \times 1_{\left\{\mathrm{c}_{\mathrm{kt}}^{\beta}=2-\mathrm{c}_{0}^{\beta}\right\}}$ and inversely, the probability to be in high, long run volatility cycle is:

$$
\operatorname{Pr}(\text { HLRC })_{\mathrm{t}}=\operatorname{Pr}\left(\mathrm{C}_{\overline{\mathrm{kt}}}^{\alpha}=\mathrm{C}_{\overline{\mathrm{kt}}}^{\beta}=\mathrm{c}_{0}^{\alpha}\right)=\Pi_{\mathrm{t}} \cdot \delta_{4}
$$

with $\delta_{4}$ a vector of dimension $4^{\overline{\mathrm{k}}}$ with dirac elements $\delta_{4 \mathrm{i}}=1_{\left\{\mathrm{c}_{\mathrm{kt}}^{\alpha}=\mathrm{c}_{0}^{\alpha}\right\}} \times 1_{\left\{\mathrm{c}_{\mathrm{kt}}^{\beta}=\mathrm{c}_{0}^{\beta}\right\}}$. This completely new set of indicators helps us understand the nature of comovement, transmission, and the effects of several events on different markets.

\section{Data and Descriptive Statistics}

\subsection{Data}

The data used in this study were the stock price indices of four countries (China, Japan, Korea, Taiwan) in East Asia, which was the Hanseng composite, Nikkei255, KOSPI, and Taiwan Weighted, respectively. The analysis period was from January 4, 1996 to December 30, 2014. The number of data points used in the study was 4083. Figure 1 represents the trend of stock price and returns of the four countries. All of the four countries experienced a great decline of the stock price index and high volatility when the global financial crisis occurred in 2008. However, the impact of the financial crisis which occurred in South Europe in 2011 was not quite as significant in China and Japan, while it was significant in Korea and Taiwan. Reviewing the trend of the stock market before the global financial crisis in 2008, each of the four countries showed distinctive individual traits by country rather than similarity to each other. Although the four countries are located geographically close to each other, stock market volatility of the four countries cannot be entirely explained by common factors. Individual factors also took an important role. 
China: Shanghai Composite

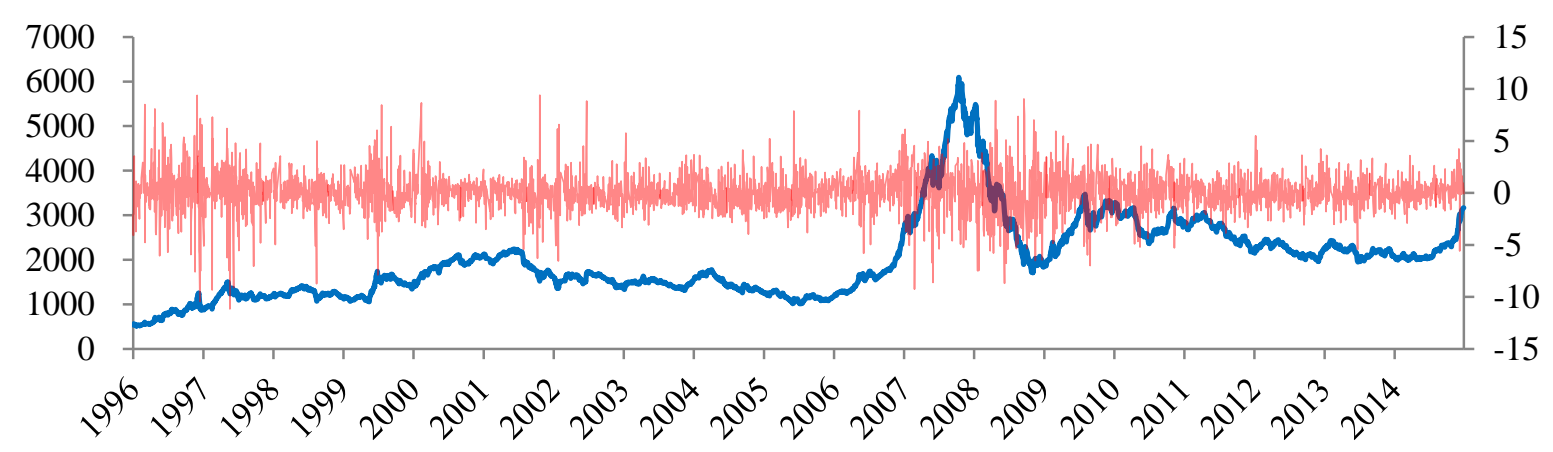

Japan : Nikkei 225

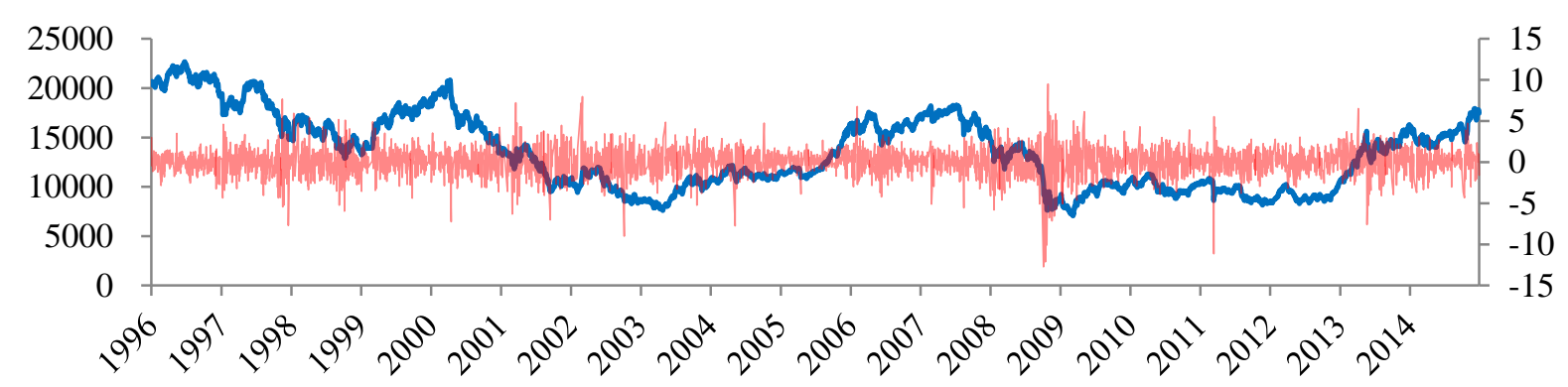

Korea : KOSPI

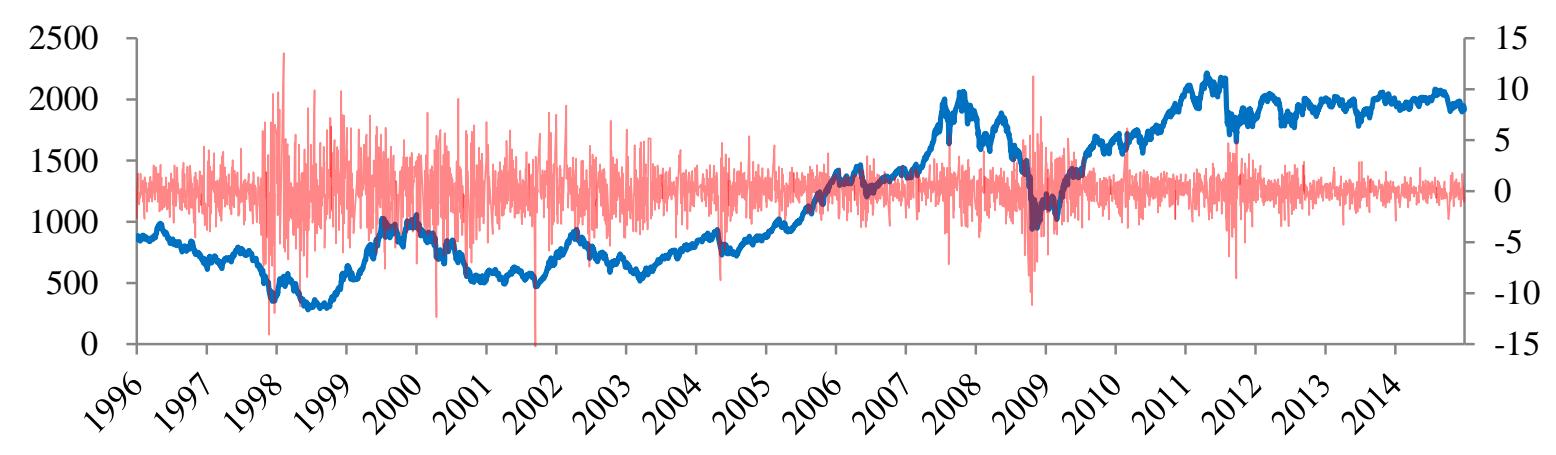

Taiwan : Taiwan Weighted

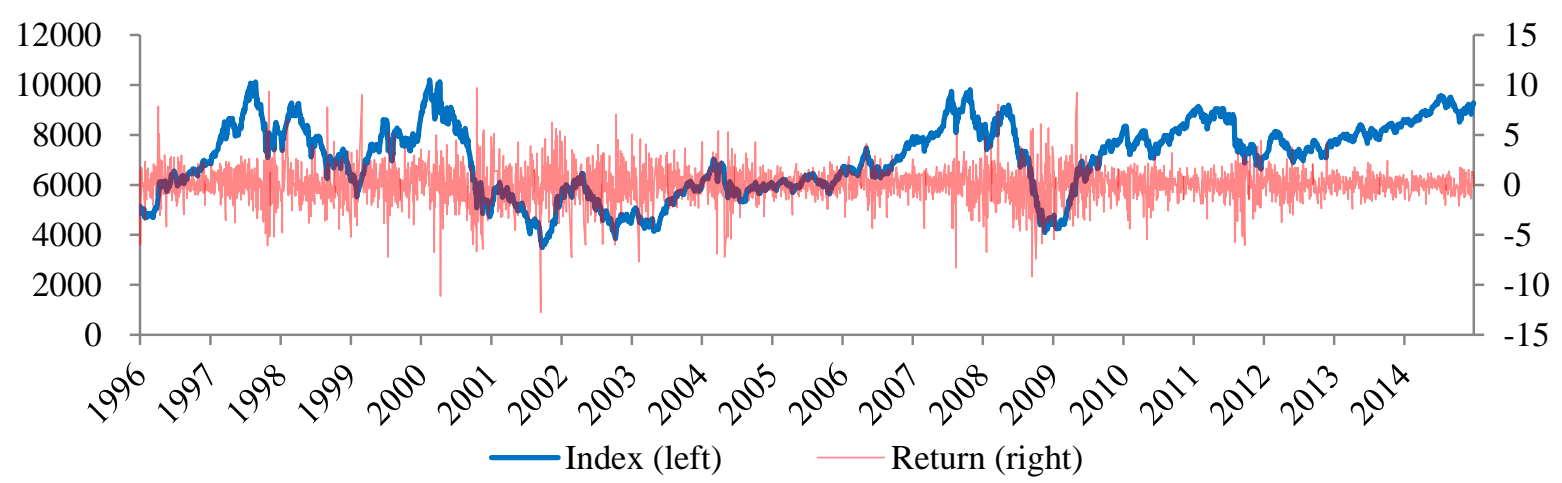

Figure 1. Stock indices and returns 


\subsection{Descriptive Statistics}

Table 1 shows the basic statistics of $\log$ rate of returns $\left(\ln \left(\mathrm{P}_{t} / \mathrm{P}_{\mathrm{t}-1}\right) \times 100\right)$ of stock price index by day. Although the average rate of returns is small enough to be close to 0 , the volatility is relatively large, which is around $1.6 \sim 2$. Especially for Korea, the absolute size of maximum and minimum rate of returns, as well as volatility, was the largest during the analysis period. The patterns of skewness and kurtosis of the four countries have left-long and fat-tailed distribution, which is a general characteristic of rate of returns. Jarque-Bera statistic shows unique characteristics of rate of returns, which does not follow the normal distribution pattern.

Table 1 . Descriptive statistics of daily equity returns in 4 countries

\begin{tabular}{lcccc}
\hline & China & Japan & Korea & Taiwan \\
\hline Mean (\%) & 0.042 & -0.003 & 0.019 & 0.015 \\
Median (\%) & 0.044 & 0.018 & 0.065 & 0.037 \\
Maximum (\%) & 9.401 & 9.494 & 13.553 & 9.716 \\
Minimum (\%) & -11.165 & -12.715 & -16.115 & -12.778 \\
Std. Dev. & 1.784 & 1.622 & 2.000 & 1.607 \\
Skewness & -0.154 & -0.471 & -0.284 & -0.263 \\
Kurtosis & 7.733 & 8.041 & 8.959 & 8.316 \\
Jarque-Bera(JB) & 3827.0 & 4474.6 & 6096.1 & 4855.2 \\
JB Prob. & 0.0 & 0.0 & 0.0 & 0.0 \\
\hline & & Correlation & & 0.17 \\
\hline China & 1 & 0.17 & 0.13 & 0.41 \\
Japan & 0.17 & 1 & 0.48 & 0.45 \\
Korea & 0.13 & 0.48 & 0.45 & 1 \\
Taiwan & 0.17 & 0.41 & & \\
\hline Nes: Retr & & & & \\
\hline
\end{tabular}

Notes: Returns are calculated as $\ln \left(\mathrm{P}_{\mathrm{t}} / \mathrm{P}_{\mathrm{t}-1}\right) \times 100$.

The correlation between Korea and Japan was 0.48 , the highest, followed by the correlation between Korea and Taiwan, which was 0.45. China show the least correlation with other countries. In the aspect of correlation, China was distinguished from the other three countries. Therefore, it seems that China stock market is isolated from other countries.

\section{Empirical Results}

\subsection{Estimation Results}

The model set in this study is the Bivariate MSM model with three volatility components for $\bar{k}=3$. It is easy for short-term analysis as well as mid and long-term analysis. Table 2-1 and Table 2-2 were the summary of estimation results of the parameters that maximize log likelihood function of the Equation (17).

Table 2-1. Estimation results of the bivariate MSM models for $\overline{\mathrm{k}}=3$

\begin{tabular}{cllllll}
\hline \multicolumn{3}{l}{ Chi na-Japan } & \multicolumn{3}{c}{ China-Korea } & \multicolumn{3}{l}{ China-Taiwan } \\
\hline $\mathrm{c}_{0}^{\alpha}$ & 1.540 & $(0.019)$ & 1.542 & $(0.019)$ & 1.545 & $(0.018)$ \\
$\mathrm{c}_{0}^{\beta}$ & 1.473 & $(0.021)$ & 1.577 & $(0.015)$ & 1.533 & $(0.016)$ \\
$\sigma_{\alpha}$ & 1.996 & $(0.103)$ & 2.007 & $(0.113)$ & 2.006 & $(0.109)$ \\
$\sigma_{\beta}$ & 1.820 & $(0.067)$ & 2.031 & $(0.211)$ & 1.631 & $(0.059)$ \\
$\gamma_{\mathrm{k}}$ & 0.858 & $(0.041)$ & 0.919 & $(0.013)$ & 0.951 & $(0.003)$ \\
$\mathrm{b}$ & 26.547 & $(6.522)$ & 34.865 & $(7.854)$ & 36.270 & $(7.671)$ \\
$\rho_{\varepsilon}$ & 0.171 & $(0.016)$ & 0.190 & $(0.017)$ & 0.196 & $(0.016)$ \\
$\lambda$ & 0.031 & $(0.164)$ & 0.000 & $(0.247)$ & 0.112 & $(0.136)$ \\
$\ln \mathcal{L}$ & -14769.0 & & -15119.0 & & -14471.0 & \\
\hline
\end{tabular}

Notes: In Table 2-1 and 2-2, estimation results are obtained by maximizing the logarithm of the likelihood in Equation (17). Values in parentheses represent standard error. 
Table 2-2. Estimation results of the bivariate MSM models for $\overline{\mathrm{k}}=3$

\begin{tabular}{cllllll}
\hline & Japan-Korea & \multicolumn{3}{c}{ Japan-Ta } & wan & \multicolumn{3}{l}{ Korea-Taiwan } \\
\hline $\mathrm{c}_{0}^{\alpha}$ & 1.489 & $(0.041)$ & 1.474 & $(0.022)$ & 1.579 & $(0.017)$ \\
$\mathrm{c}_{0}^{\beta}$ & 1.535 & $(0.018)$ & 1.527 & $(0.017)$ & 1.528 & $(0.018)$ \\
$\sigma_{\alpha}$ & 2.303 & $(0.192)$ & 1.825 & $(0.075)$ & 1.997 & $(0.390)$ \\
$\sigma_{\beta}$ & 2.305 & $(0.096)$ & 1.634 & $(0.057)$ & 1.635 & $(0.058)$ \\
$\gamma_{\mathrm{k}}$ & 0.063 & $(0012)$ & 0.876 & $(0.029)$ & 0.926 & $(0.016)$ \\
$\mathrm{b}$ & 5.730 & $(1.528)$ & 32.751 & $(7.495)$ & 42.799 & $(22.833)$ \\
$\rho_{\varepsilon}$ & 0.547 & $(0.012)$ & 0.454 & $(0.014)$ & 0.535 & $(0.012)$ \\
$\lambda$ & 0.681 & $(0.060)$ & 0.675 & $(0.066)$ & 0.811 & $(0.043)$ \\
$\ln \mathcal{L}$ & -14314.0 & & -13942.0 & & -14038.0 & \\
\hline
\end{tabular}

First of all, most parameters are shown as statistically significant. As for Japan and Korea, $\gamma_{\mathrm{k}}$, a switching probability of short-term volatility factor was 0.063 , which is relatively smaller than others. That means the cycle is that long. It seems to be related to the highest correlation of 0.48 between Korea and Japan as shown in Table 1. The estimated parameter $\lambda$ refers to the correlation between information arrivals or the unconditional correlation between the occurrences of jumps of the components in the two markets.

The notable thing is that when China is included, $\lambda$ is statistically insignificant and close to 0 . On the other hand, if China is not included, not only is $\lambda$ statistically significant, but also it has big value that falls into the range of $0.6 \sim 0.8$. Such results indicate that China is different from the other three countries in terms of information arrivals. This finding is consistent with Hsiao et al. (2003). In other words, Japan, Korea, and Taiwan have high correlation with information arrivals, though there may be a slight difference in degree, they would show similar jump reactions to external shocks. On the other hand, China is hardly affected by external shocks, even when there were information arrivals to the stock markets of other countries. Rather, China is relatively resistant to external shocks. Depending on the inclusion of China, the result varies. It is same with $\rho_{\varepsilon}$, which is correlated with error term. Such results have something in common with the correlation with basic statistics reviewed above. Therefore, it is assumed that the estimation results of the bivariate MSM model represents the characteristics of data shown in basic statistics. As a result, what we learn from estimation results of parameters is that China is different from the other three countries in terms of correlation and that China is not vulnerable to external shock, compared to the three countries.

\subsection{Comovements}

Figure 2 shows joint probability to be in the highest volatility state. There are common things and differences in terms of volatility depending on country. The common thing is that all countries had high stock market volatility due to the global financial crisis in 2008. The difference is that during the East Asian crisis in 1997 and European financial crisis in 2011, where the reactions varied depending on country. As for Japan and China, there was relatively little impact from the East Asian crisis of 1997 and financial crisis in South Europe of 2011. Thus, these crises are interpreted as a local shock. However, the global financial crisis of 2008 turned the short-term, mid and long-term volatility of all countries, including Japan and China, to be high and it was interpreted as a global shock. Liow (2015) identified that the South European financial crisis of 2011 was identified as a local shock. It was consistent with the results of this study in the aspect that China and Japan had little impact from the South European financial crisis, while Korea and Taiwan were affected greatly. Huyghebaert and Wang (2010) find that most East Asian stock markets, except for those in Mainland China, are Granger cuased by the US market during 2008 global financial crisis. And their findings reveal that stock markets in Mainland China remain isolated from those in East Asia and the world, despite the country's huge economic and financial development. Dekker et al. (2001) and Bessler and Yang (2003) argue that Japan is a relatively isolated market in normal market circumstances, it means that Japan neither influences nor is affected by innovations in other countries. Regarding South Korea, Yang et al. (2003) argue that it is a fairly endogenous market, as it reacts strongly to shocks in other markets without having much impact itself on these markets. These previous results seem to be consistent with our results. But Ghosh et al. (1999) and Dekker et al. (2001) document that the Taiwanese stock market is an isolated market. However, the results show Taiwan can be classified as highly endogenous market just like South Korea. 

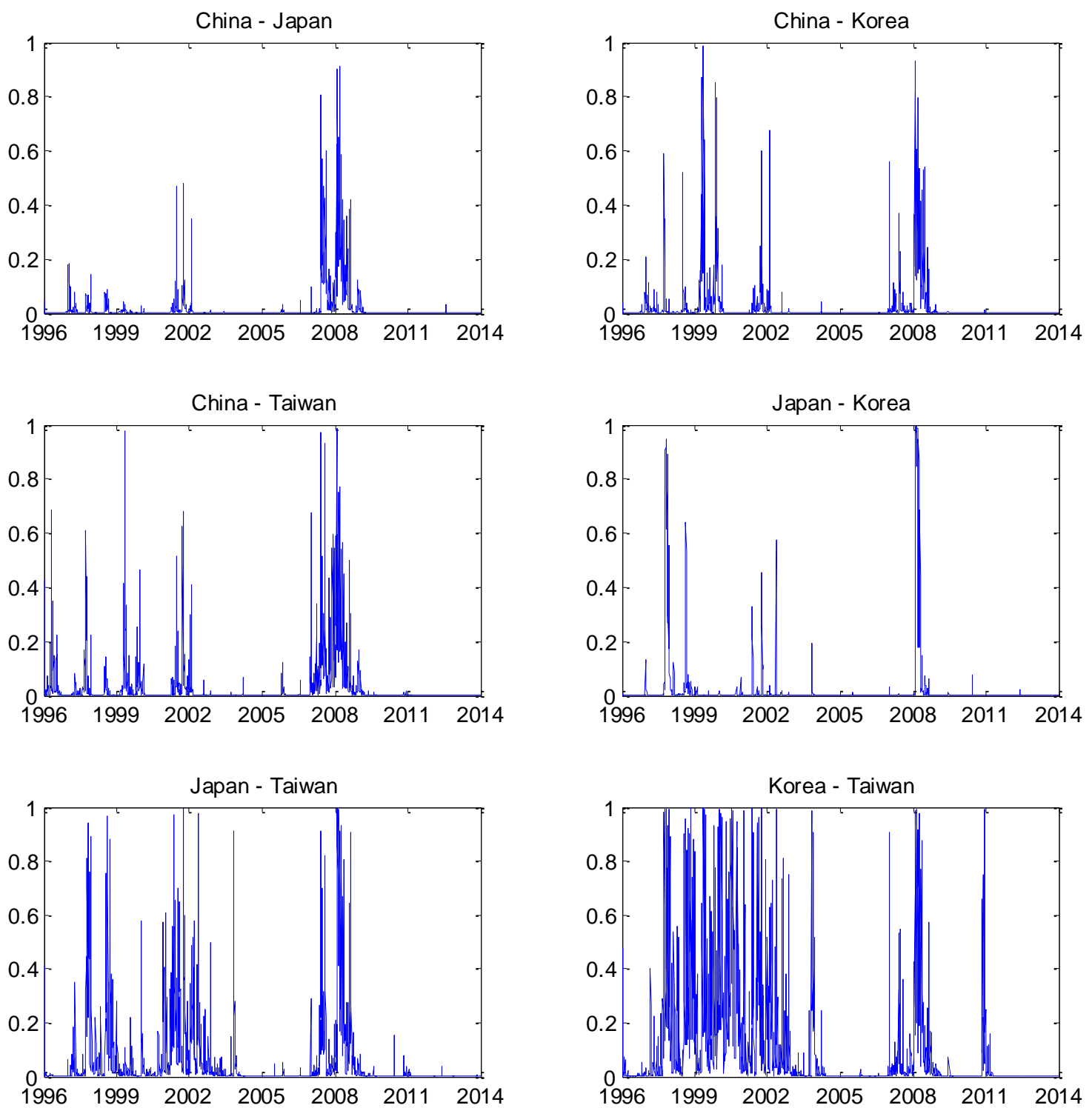

Figure 2. Joint Crisis Probability

Notes: Subtitle (A-B) means joint crisis probability, Prob (A is crisis and B is crisis). 
Figure 3 represents covariance. Like joint risk probability in Figure 2, Korea and Taiwan had high covariance due to high volatility caused by the financial crisis in South Europe in 2011.
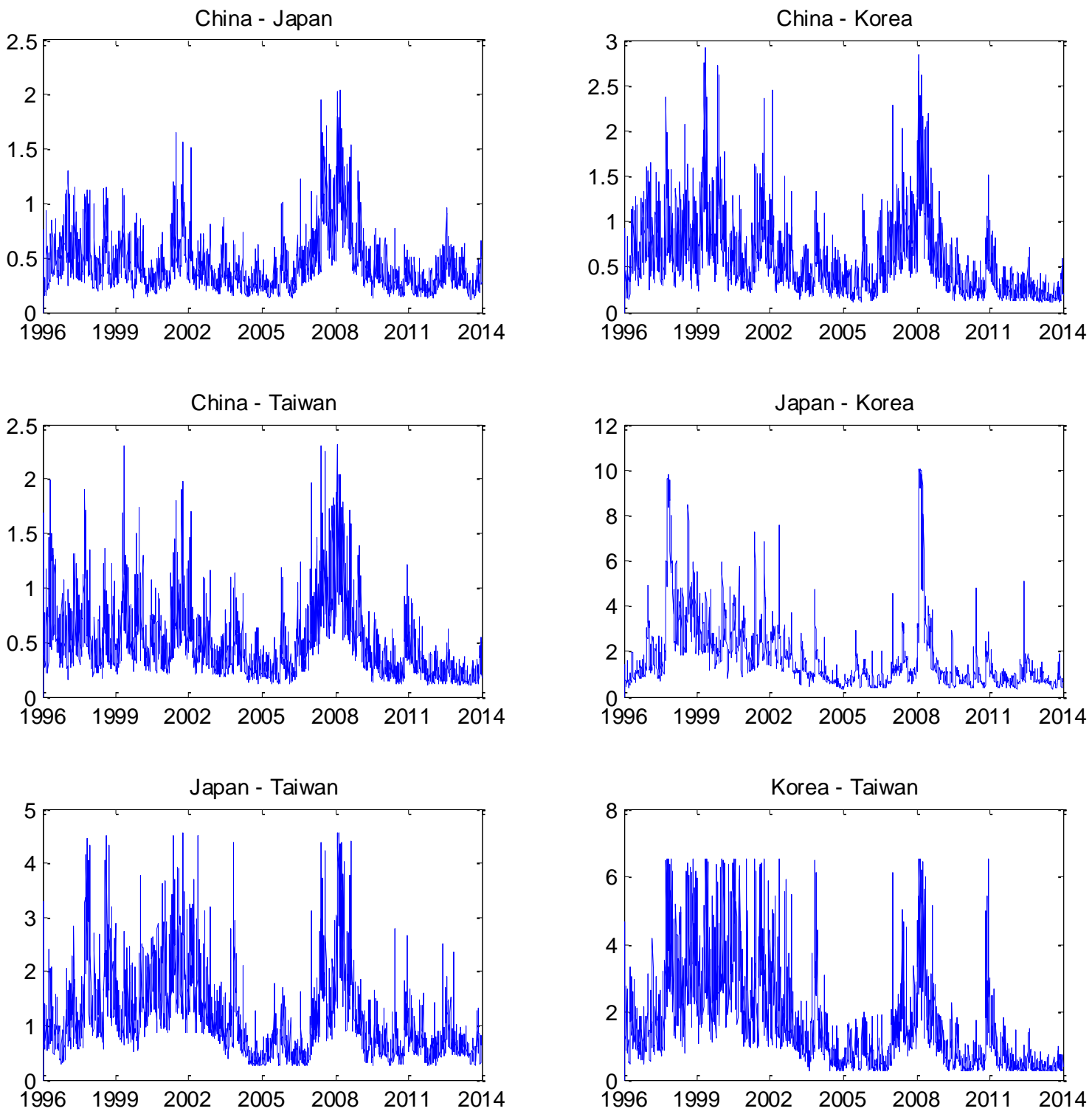

Figure 3. Covariance

Notes: Subtitle (A-B) means Covariance between A and B, Cov (A, B).

\subsection{Comovements}

Figure 4 shows the probability of extreme volatility comovement defined in Equation (22). It is the conditional probability of being in the state of high volatility for the market $\beta$, given that $\alpha$ experiences extreme volatility. In order to review the trend of conditional crisis probability as done by Idier (2011), we superimposed the 50-day moving average. 

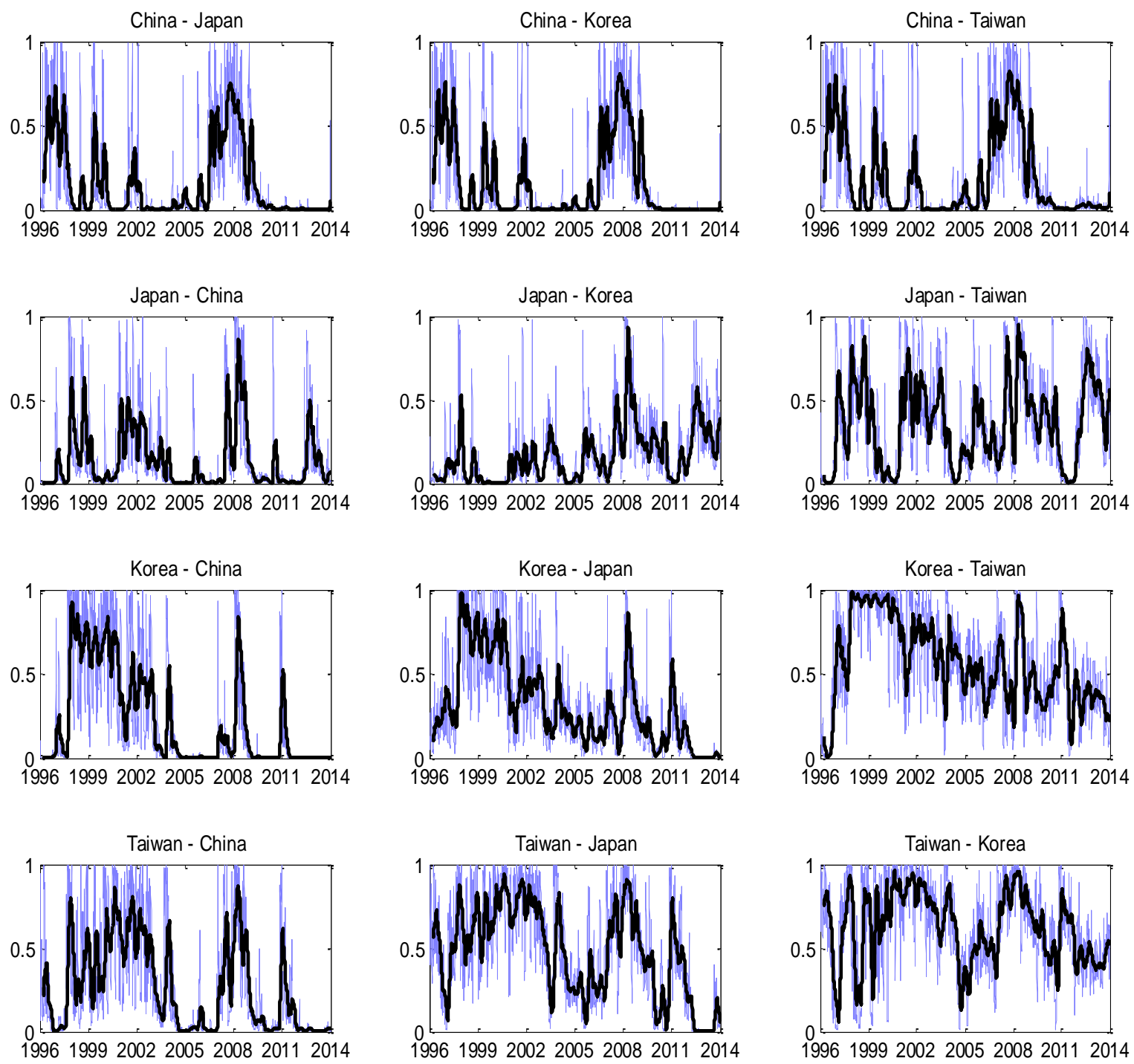

Figure 4. Conditional Crisis Probability

Notes: (A-B) means the conditional crisis probability, Prob (A is crisis/B is crisis). The black solid line is the 50-day moving average.

The conditional crisis probability of China in the first row in Figure 4 did not show a significant difference, even if the country in the denominator is changed. As shown in the correlation and joint crisis probability stated above, it indicates that there is little correlation between China and other countries. In the end of 2014, the conditional crisis probability of China became high regardless of the country in the denominator. It was because other countries showed relatively low volatility in stock market, while China showed high volatility. As recent issues of low growth and a stock market bubble have emerged in China, stock market volatility in China may be expanded to other countries in the future. However, this study was completed at the end of 2014 at which there was no significant movement in the stock markets of other countries.

The conditional crisis probability of Japan on the 2nd row of Figure 4 showed increasing intensity and frequency in China, Korea, and Taiwan, in that order. Graphs on the 3rd row of Figure 4 indicate conditional crisis probability of Korea. They showed increasing intensity and frequency like Japan in China, Japan, and Taiwan, in that order. The 4th row in Figure 4 showed the conditional crisis probability of Taiwan, which is similar to Korea. In particular, we can see that there was contagion of high volatility between Korea and Taiwan.

In the sections of the East Asian crisis of 1997 and dot-com bubbles of 2002 on the graphs, China and Japan had great and persistent influence on Korea and Taiwan. After then, they had partial influence on only the crisis' in 2008 and 2011, which was relatively not persistent. It means that Korea and Taiwan's stock markets had volatility spillovers compared 
to China and Japan. Therefore, it is interpreted that China and Japan had different distinguishing characteristics from Korea and Taiwan.

\subsection{Long-term Volatility Cycles}

If two countries had long-term volatility factors in a high volatility state, the possibility that high volatility of the two countries will be sustained for a long time gets higher. Compared to short-term volatility factors, comovement of long-term volatility factors will give greater impact to the market. Figure 5 shows how comovement occurs in two countries in a long-term high volatility state.
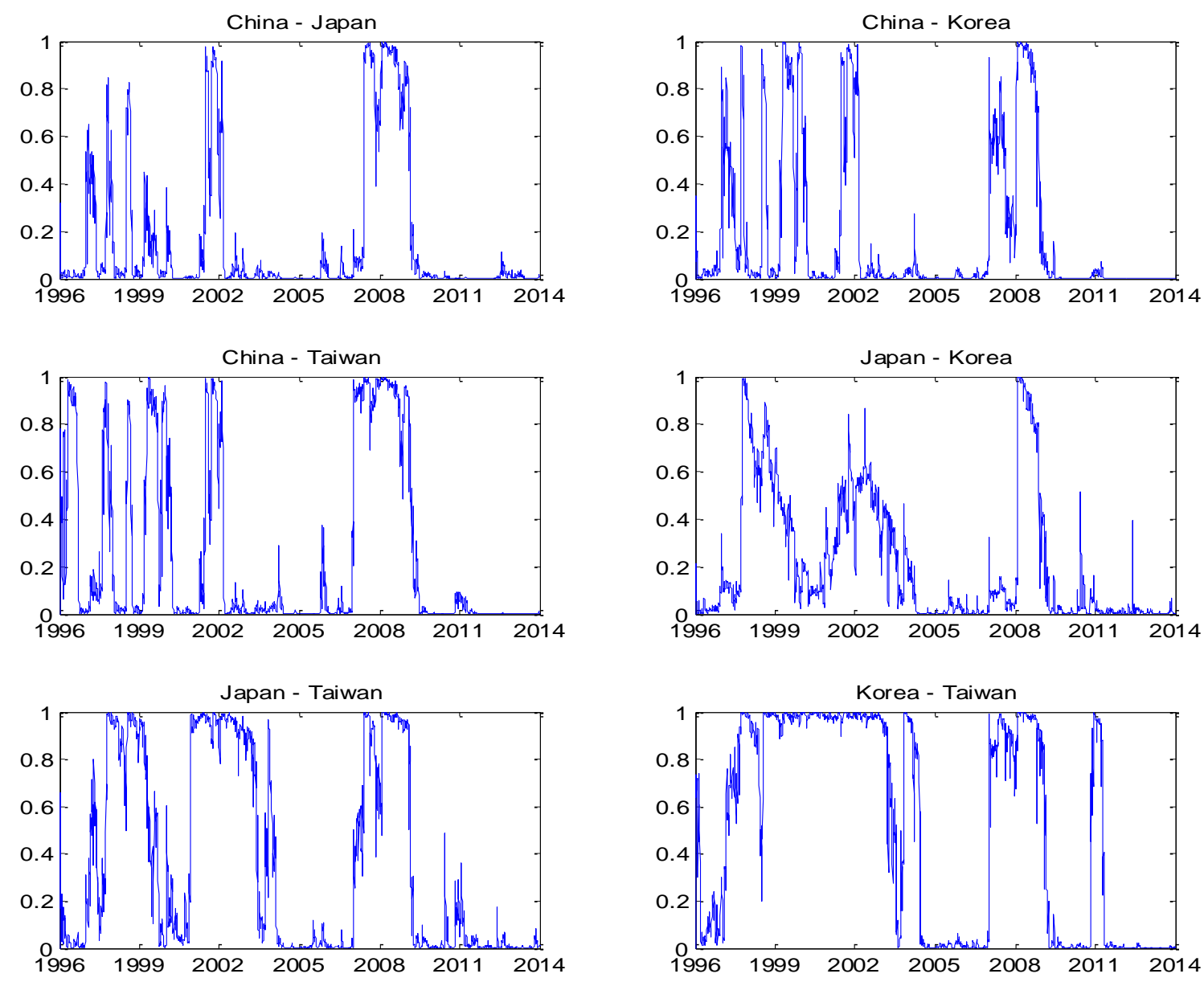

Figure 5. Long-term high volatility cycle

Notes: (A-B) means long-term high volatility cycle between A and B.

Seeing the comovement in long-term high volatility state, the high volatility state sustained for a long time in every country in the global financial crisis of 2008. On the other hand, it varies by country in other crisis sections. In particular, the financial crisis in South Europe in 2011 had great influence on Korea and Taiwan. As for China and other countries, comovement of long-term high volatility state occurred very frequently due to the East Asian crisis in 1997 and collapse of the dot-com bubble triggered from USA in 2002, although it was not sustained for long. In 2008, long-term high volatility state was sustained for quite a long time due to the global financial crisis, but the European financial crisis in 2012 did not give much impact. As for Japan and Korea, persistency of crisis in 1997 in the two countries was a little bit longer than the crisis in 2008. Although the crisis caused by collapse of the dot-com bubble in USA in 2002 was not quite greater than other two crises in terms of depth, it persisted for quite long time. The East Asian financial crisis of 1997 significantly increased stock price volatility of various countries in East Asia, including Korea. As for Japan, it was not affected much by the shock, but there was contagion of long-term high volatility. As for Japan and Taiwan, they showed high comovement of long-term high volatility in the crisis sections of 1997 and 2002. However, in the crisis of 2011, the impact was relatively small. As for Korea and Taiwan, they were similar in terms of long-term high volatility. The high volatility persisted from the East Asian crisis in 1997 and continued till the collapse of the dot-com bubble that started in USA in 2002. In the crises of 2008 and 2011, comovement of long-term volatility 
state was shown to be high. Unlike China or Japan, Korea and Taiwan were affected greatly by the crisis of 2011.

Figure 6 showed long-term comovement of low volatility. Unlike the long-term comovement of high volatility, low volatility was strongly shown mainly in the non-crisis sectors. The peculiar thing is that if China is included, the long-term comovement of low volatility was lowered from 1 to 0.5 in the end of 2014. It was affected by the recent fall of stock market in China and we need to look over the trend carefully. If China is not included, low volatility is shown to continue in the long run, which reflects the low volatility in the stock market of each country, which has occurred since 2 3 years ago.
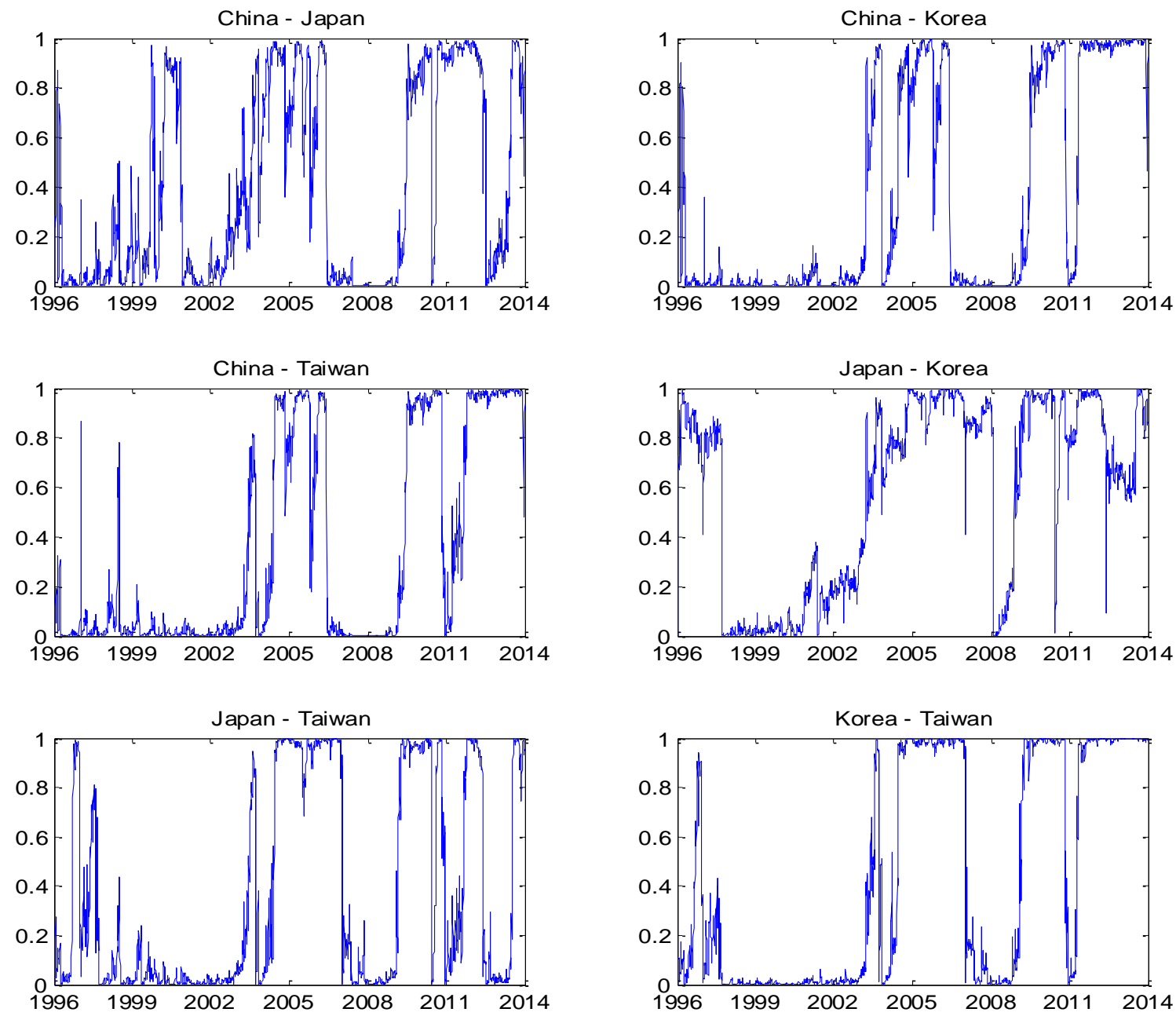

Figure 6. Long-term low volatility cycle

Notes: (A-B) means long-term low volatility cycle between A and B.

\section{Conclusion}

This study analyzed comovement and contagion of volatility in stock markets of the four countries in East Asia, which are China, Japan, Korea, and Taiwan, with the BMSM model of Calvet et al. (2006). In particular, reviewing additional risk indicators such as probability of a crisis and extreme comovement indicator of Idier (2011), this study defined the measurement index more specifically.

As a result, it was found that China did not have significant correlation with the other three countries. Also, the influence of financial crises on the countries in East Asia varies depending on country. Korea and Taiwan turned out to be vulnerable to external shock, contrasted with China and Japan which did not. Especially, both financial crises in East Asia in 1997 and in South Europe in 2011 were identified as local shocks, while the financial crisis in 2008 was identified as a global shock because volatility of all countries increased short-term and/or mid and long-term volatility. Owing to the concerns on the low growth of China in recent times and its aging society, stock market volatility increased not only in China, but also in neighboring countries. However, the analysis result of time series data of the past demonstrated that China did not have correlation with other countries. In the aspect that China was relatively stable 
from external shock, it is hard to forecast the contagion effect of the internal shock of China on neighboring countries. However, it is necessary to prepare for contagion risk that might occur due to the increase in stock market volatility in China in the future. It is because contagion effect of stock market volatility in China or Japan had big influence on Korea and Taiwan, seeing the conditional risk probability of the crisis sector of 1997. After then, stock market volatility in China and Japan was reduced greatly, which lowered the probability of significant impact. However, as stock market volatility in China has been increasing since the end of 2014, there is high possibility of contagion risk to East Asian countries which are vulnerable to external shock. As comovement of long-term low volatility is reduced in China, we need to take notice of the effect of increasing volatility expanding to other countries in the short run or in the mid and long run, and the potential result in comovement of long-term high volatility.

\section{References}

Bessler, D., \& Yang, J. (2003). The structure of interdependence in international stock markets, Journal of International Money and Finance, 22(2), 261-287.

Bollerslev, T. (1986). Generalized Autoregressive Conditional Heteroskedasticity, Journal of Econometrics, 31, 307-327. https://doi.org/10.1016/0304-4076(86)90063-1

Calvet, L. E., \& Fisher, A. J. (2004). How to forecast long-run volatility: Regime-switching and the estimation of multifractal processes. Journal of Financial Econometrics, 2, 49-83. https://doi.org/10.1093/jjfinec/nbh003

Calvet, L. E., Fisher, A. J., \& Thompson, S. (2006). Volatility comovement: A multifrequency approach. Journal of Econometrics, 31, 179-215. https://doi.org/10.1016/j.jeconom.2005.01.008

Choi, W. S. (2006). Dynamic Nature of Conditional Correlation in East-Asian Equity Markets, Asian Review of Financial Research, 19(2), 155-187.

Click, R. W., \& Plummer, M. G. (2005). Stock market integration in ASEAN after the Asian financial crisis, Journal of Asian Economics, 16, 5-28. https://doi.org/10.1016/j.asieco.2004.11.018

Dekker, A., Sen, K., \& Young, M. (2001). Equity market linkages in the Asia Pacific region: A comparison of the orthogonalized and generalized VAR approaches, Global Finance Journal, 12(1), 1-33. https://doi.org/10.1016/s1044-0283(01)00025-4

Diebold, F. X., \& Yilmaz, K. (2009). Measuring financial asset return and volatility spillovers with application to global equity markets, Economic Journal, 119, 158-171. https://doi.org/10.1111/j.1468-0297.2008.02208.x

Engle, R. F. (1982). Autoregressive conditional heteroskedasticity with estimates of the variance of U. K. inflation. Econometrica, 50, 987-1008. https://doi.org/10.2307/1912773

Ghosh, A., Saidi, R., \& Johnson, K. (1999). Who moves the Asia-pacific stock markets - US or Japan? Empirical evidence based on the theory of co-integration, The Financial Review, 34(1), 139-170.

Hamilton, J. D. (1989). A new approach to the economic analysis of nonstationary time series and the business cycle. Econometrica, 57, 357-384. https://doi.org/10.2307/1912559

Hsiao, F. S. T., Hsiao, M. C. W., \& Yamashita, A. (2003). The impact of the US economy on the Asia-Pacific region: Does it matter?, Journal of Asian Economics, 14(2), 19-241.

Huyghebaert, N., \& Wang, L. (2010). The co-movement of stock markets in East Asia: Did the 1997-1998 Asian financial crisis really strengthen stock market integration? China Economic Review, 21, 98-112. https://doi.org/10.1016/j.chieco.2009.11.001

Idier, J. (2011). Long-term vs. short-term comovements in stock markets: The use of markov-switching multifractal models. The European Journal of Finance, 17, 27-48. https://doi.org/10.1080/13518470903448440

Johnson, R., \& Soenen, L. (2002). Asian economic integration and stock market comovememt, The Journal of Financial Research, 25(1), 141-157.

Jorion, P. (1989). The linkages between national stock markets, In R. Z. Aliber (Ed.), The Handbook of International Financial Management (759-781), Irwin, Illinois: Dow Jones.

Khan, S., \& Park, K. W. (2009). Contagion in the stock markets: The Asian financial crisis revisited, Journal of Asian Economics, 20, 561-569. https://doi.org/10.1016/j.asieco.2009.07.001

Kuper, G. H., \& Lestano, (2007). Dynamic conditional correlation analysis of financial market interdependence: An application to Thailand and Indonesia, Journal of Asian Economics, 18, 670-684. https://doi.org/10.1016/j.asieco.2007.03.007

Lee, S. H., \& Kim, M. J. (2015). Performance of Long-Term KOSPI200 Returns Volatility Forecast Using Markov 
Switching Multifractal Model. working paper.

Leong, S. C., \& Felmingham, B. (2003). The interdependence of share markets in the developed economies of East Asia, Pacific-Basin Finance Journal, 11, 219-237. https://doi.org/10.1016/S0927-538X(03)00002-7

Liow, K. (2015). Conditional volatility spillover effects across emerging financial markets, Asia-Pacific Journal of Financial Studies, 44, 215-245. https://doi.org/10.1111/ajfs.12087

Lux T. (2007). Higher Dimensional Multifractal Processes: A GMM approach, Journal of Business and Economic Statistics, 26, 194-210. https://doi.org/10.1198/073500107000000403

Palac-McMiken, E. D. (1997). An examination of ASEAN stock markets: a cointegration approach, ASEAN Economic Bulletin, 13, 299-311. https://doi.org/10.1355/AE13-3B

Park, J. W. (2010). Comovement of Asian stock markets and the U.S. influence, Global Economy and Finance, 3, 76-88.

Roca, E. D., Selvanathan, E. A., \& Shepherd, W. F. (1998). Are the ASEAN Equity Markets Interdependent?, ASEAN Economic Bulletin, 15, 109-120. https://doi.org/10.1355/AE15-2A

Sharma, S. C., \& Wongbangpo, P. (2002). Long-term trends and cycles in ASEAN stock marekts, Review of Financial Economics, 11, 299-315. https://doi.org/10.1016/S1058-3300(02)00062-9

Tan, K. B., \& Tse, Y. K. (2002). The integration of the East and South-East Asian equity marekts, International Center for the Study of East Asian Development, Working Paper, No. 2002-11.

Thao, T. P., Daly, K., \& Ellis, C. (2013). Transmission of the Global Financial Crisis to the East Asian Equity Markets. International Journal of Economics and Finance, 5(5), 171-183. https://doi.org/10.5539/ijef.v5n5p171

Toyoshima, Y., \& Hamori, S. (2013). Asymmetric dynamics in stock market correlations: Evidence from Japan and Singapore, Journal of Asian Economics, 24, 117-123. https://doi.org/10.1016/j.asieco.2012.08.001

Yang, J., Kolari, J.. \& Min, I. (2003). Stock market integration and financial crisis: The case of Asia, Applied Financial Economics, 13(7), 477-486. https://doi.org/10.1080/09603100210161965

Yang, L. (2013). Volatility spillovers among the U.S. and Asian stock markets: A comparison between the periods of Asian currency crisis and subprime credit crisis, Working Paper.

Yilmaz, K. (2010). Return and volatility spillovers among the East Asian equity markets. Journal of Asian Economics, 21(3), 204-313. https://doi.org/10.1016/j.asieco.2009.09.001

\section{Copyrights}

Copyright for this article is retained by the author(s), with first publication rights granted to the journal.

This is an open-access article distributed under the terms and conditions of the Creative Commons Attribution license which permits unrestricted use, distribution, and reproduction in any medium, provided the original work is properly cited. 